\title{
Reply regarding thymic sail sign
}

\author{
Goya Enriquez
}

Received: 20 October 2009 / Accepted: 21 October 2009 / Published online: 19 January 2010

(C) Springer-Verlag 2010

Sir,

I and my co-authors appreciate Dr. Han's careful reading of our article on pitfalls of chest imaging in children [1] and his comments on visualization of the sail sign on chest radiographs in adults, which mainly represent fat tissue extending from the anterior mediastinum [2].

We are aware that thymic remnants may exist beyond the age of 8 years and are not usually identified on chest radiographs, although they can be visualized on chest CT, as we have encountered in our experience with children over this age. Our intent with the time frame of 8 years was to alert paediatric radiologists to the fact that widening of the anterior mediastinum (the thymus does not always manifest as a sail sign) on plain films in older children should not be assumed to be due to the normal thymus. Other causes should be investigated.

\section{References}

1. Enriquez G, Garcia-Peña P, Lucaya J (2009) Pitfalls in chest imaging. Pediatr Radiol 39(Suppl 3):356-368

2. Han DH (2009) Thymic sail sign: unique to paediatric chest radiographs? Pediatr Radiol. doi:10.1007/s00247-009-1460-x

G. Enriquez $(\bowtie)$

Department of Pediatric Radiology,

Vall d'Hebron Children's Hospital,

P. Vall d'Hebron 119-129,

Barcelona 08035, Spain

e-mail: genriquez@vhebron.net 